\title{
GCU
}

Glasgow Caledonian

University

University for the Common Good

\section{Partial discharge behavior under HVDC superimposed with transients}

\author{
Azizian Fard, M.; Reid, A.J.; Hepburn, D.M.; Farrag, M.
}

Published in:

51st International Universities Power Engineering Conference (UPEC)

DOI:

10.1109/UPEC.2016.8114059

Publication date:

2017

Document Version

Author accepted manuscript

Link to publication in ResearchOnline

Citation for published version (Harvard):

Azizian Fard, M, Reid, AJ, Hepburn, DM \& Farrag, M 2017, Partial discharge behavior under HVDC

superimposed with transients. in 51st International Universities Power Engineering Conference (UPEC). IEEE, pp. 1-5. https://doi.org/10.1109/UPEC.2016.8114059

\section{General rights}

Copyright and moral rights for the publications made accessible in the public portal are retained by the authors and/or other copyright owners and it is a condition of accessing publications that users recognise and abide by the legal requirements associated with these rights.

Take down policy

If you believe that this document breaches copyright please view our takedown policy at https://edshare.gcu.ac.uk/id/eprint/5179 for details of how to contact us. 


\title{
Partial Discharge Behavior under HVDC Superimposed with Transients
}

\author{
M. Azizian Fard, A. J. Reid, D. M. Hepburn and M. Emad Farrag \\ Glasgow Caledonian Universality, UK \\ m.a.fard@gcu.ac.uk
}

\begin{abstract}
Transient overvoltages are inevitable phenomena in power systems. They occur in high voltage direct current systems for much the same as the reasons they happen in high voltage alternating current systems and could be of either internal or external origin. Moreover, the switching operation of the power electronic valves in HVDC converters add to these transient sources. The effects of such transient overvoltages become more critical in the case of non-restoring insulation media like solid dielectrics that form the main insulation media of extruded HVDC power cables. In addition, the intrinsic behavior of solid dielectric under DC fields results in space charge accumulation due to inhomogeneity of the insulation, increasing the likelihood of a fault during overvoltage incidents or even during normal operations like polarity reversal. This paper presents the results of PD measurements that have been conducted on artificial test samples at HVDC superimposed with standard switching overvoltages and operational polarity reversal, which are common in modern converter schemes. The results show that under such transient conditions, PD occurs with higher repetition than the normal voltage level in the test sample. The results of this investigation should be of interest to network operators for asset management on fleets of HVDC cables that may typically be subject to the reported transients and polarity reversal effects.
\end{abstract}

Index Terms-- HVDC transmission; Insulation; Partial Discharge; Polarity reversal; Power system transients.

\section{INTRODUCTION}

Transients in electrical systems occur due to sudden changes in the circuit conditions. Such changes can be the result of the abrupt appearance of external energy or release of internally stored energy due to lightning strikes or switching operations, respectively. These phenomena are inevitable; thus, they should be considered in insulation coordination both in high voltage alternating current (HVAC) and high voltage direct current (HVDC) systems [1]. Conventionally, polymeric cables have been used in voltage source converter (VSC) schemes, hence, these cables would not be expected to experience normal polarity reversal (e.g. for power exchange) and they are mostly terminated in converter stations at both ends. However with the advancement in HVDC cable technology and motivation towards using environmentally friendly materials, polymeric cables are also used in line commutated converter (LCC) schemes [2]. Nevertheless, polymeric cables still suffer from space charge accumulation (due to manufacturing imperfections and the natural interaction of the DC field with the insulation material) even under the influence of systematic operations such as load cycling or polarity reversal (in LCC schemes). This could result in locally enhanced electric fields within the insulation that might affect its electrical strength. Furthermore, in the case of transient overvoltages, the superposition of an opposite-polarity voltage could result in transient polarity reversal. The Laplacian field of such externally introduced sources in association with the Poisson field resulting from the accumulated space charges could lead to a locally enhanced net electric field beyond the insulation breakdown field, affecting the insulation integrity [3, 4]. The latter case could occur in cable based HVDC systems or hybrid configurations involving overhead lines and buried (underground or submarine) cables. Abrupt changes in the circuit conditions on one side could impact the other side. Therefore, the overvoltages occurring in the AC side could transfer to the DC side through interfacing apparatus (e.g. converter transformers) where transients are more threatening to insulation integrity [5].

The effect of transients on insulation, particularly partial discharge activity within the cable under AC regimes has been thoroughly investigated and the phenomenon is well understood [6-8]. However, less research has been devoted to the transient effects on PD occurring in solid dielectrics under DC fields, particularly polarity reversal and DC superimposed with transient overvoltages. So in this study the effects of such incidents (of external and internal origin) will be investigated based on empirical observation in range of experiments that have been conducted under laboratory conditions on well-defined insulation defect samples.

\section{TRANSIENTS IN HVDC SYSTEMS}

Transients occur in power systems due to the influence of external or internal sources. Lightning strikes are a major external cause of transient overvoltages that over-stress the insulation system, leading to potential failures. Lighting incidents can hit a main pole directly or strike adjacent equipment leading to induced overvoltages on the main pole. This rarely happens in underground cable systems, but the increasing trends towards HVDC transmission in offshore interlinks increase its likelihood [9]. Additionally, a lightning strike can hit the DC side directly or be transferred from the AC side of the overhead transmission lines through the 
converter transformer to the DC side [10], over-stressing the interlinked cable systems to a greater or lesser degree depending on the transient magnitude and impingement time. For insulation testing and analysis purposes, a lightning impulse voltage wave characteristic (front-time/tail-time) is generally considered to be $1.2 / 50 \mu \mathrm{sec}$ [11].

The second category of transients originates from the power systems themselves: switching impulses, converter disturbances [12] and bushing flashover of converter transforms [13]. Switching impulses could occur due to circuit breaker operation (protection) or as result of power system response to load rejection. According to IEC 60060-1 the waveform characteristic (front time/tail time) of 250/2500 $\mu$ s should be employed to simulate such transients for equipment withstand tests [14]. Transient overvoltages due to converter disturbances are: malfunction of valves (misfire or firethrough) as a result of failures in converter control or valve firing circuits which leads to voltage oscillations on the DC side; commutation failure (single or double) could appear due to changing conditions in AC side (e.g. voltage sags) and DC side (e.g. high current) in association with controlling circuitry which produce transient voltage reversal on the DC side. Furthermore, transient overvoltage might be induced due to pole-to-ground faults occurring in a symmetrical monopole or in a bipole configuration. The magnitude and time duration of such overvoltages depend on the grounding scheme of the HVDC system [15-17].

These overvoltages could superimpose the DC side voltage in both cases: either in the same polarity as the DC link or in the opposite polarity. Fig. 1 shows the two cases of superimposed overvoltages [3]. The electric field resulting from this overstress in association with the field caused by the space charge already built up in the cable insulation (particularly polymeric cables) can lead to increased or decreased net electric field depending on the type of the space charge (homocharges or hetrorocharges [18]). In the case of increased net field, the cable insulation could face breakdown $[3,19]$.
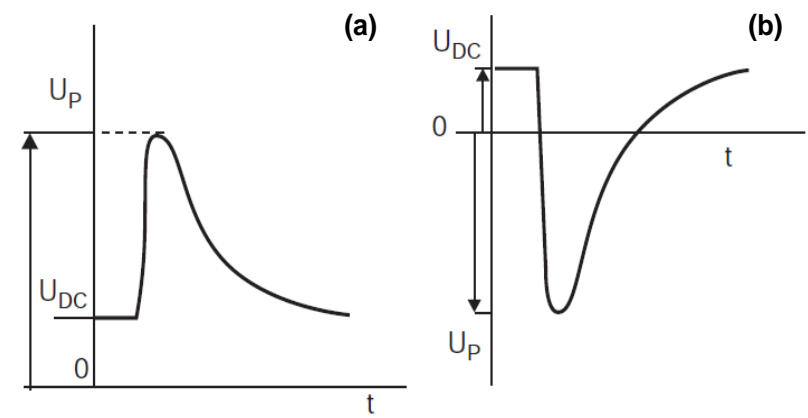

Fig. 1. Typical overvoltages: superimposed on DC voltage (a) same polarity and (b) opposite polarity [3].

\section{TeSt SetuP AND PROCEDURE}

The PD test setup comprising HV supply, control system and measurement circuit is shown in Fig. 2. The test waveforms, polarity reversal and DC superimposed with switching impulses, were generated in a stand-alone PC running LabVIEW and a programmable arbitrary signal generator, respectively. These waveforms were then fed into a high voltage amplifier (HV Amp) through an interfacing data acquisition (DAQ) card. The amplifier's output was connected to a test sample (a void of $0.95 \mathrm{~mm}$ in diameter embedded in a slab of epoxy resin with $4 \mathrm{~mm}$ thickness). The voltage gain of the amplifier is $3000 \mathrm{~V} / \mathrm{V}$, which is capable of generating a maximum voltage of $30 \mathrm{kV}$ in both polarities $( \pm 30 \mathrm{kV})$. In order to detect PD pulse current signals, an HFCT sensor was clamped around the ground wire of the test sample. The sensitivity of the HFCT was $4.3 \mathrm{mV} / \mathrm{mA} \pm 5 \%$ in the frequency range $200 \mathrm{kHz}-19 \mathrm{MHz}$. The output of the HFCT sensor was connected to a digital oscilloscope through a coaxial cable for data acquisition. The oscilloscope (LeCroy 7300) has a bandwidth of $3 \mathrm{GHz}$ and a maximum sampling rate of $20 \mathrm{GS} / \mathrm{s}$.

\section{EXPERIMENTAL}

\section{A. PD Activity Under Operational Polarity Reversal}

Polarity reversals occur in the system depending on the type of HVDC link. An interconnector between countries normally delivers power in one direction for long periods, months or years, e.g. the 2000MW UK - France link. Others, such as the UK - Ireland link typically reverse power flow once per day. A link embedded within a synchronous AC network may have more power reversals per day. Generally, the transition time between the polarities takes about one second. In order to investigate the influence of polarity reversal transition of HVDC fields on PD activity within the prepared solid insulation test sample, the steady state DC level of the applied test voltages were specified to be lower than the PD inception level of the sample, and the transition time between the polarities was set to one second. Figs. 3 and 4 illustrate the PD signals that were measured under polarity reversal from negative to positive and positive to negative, respectively.

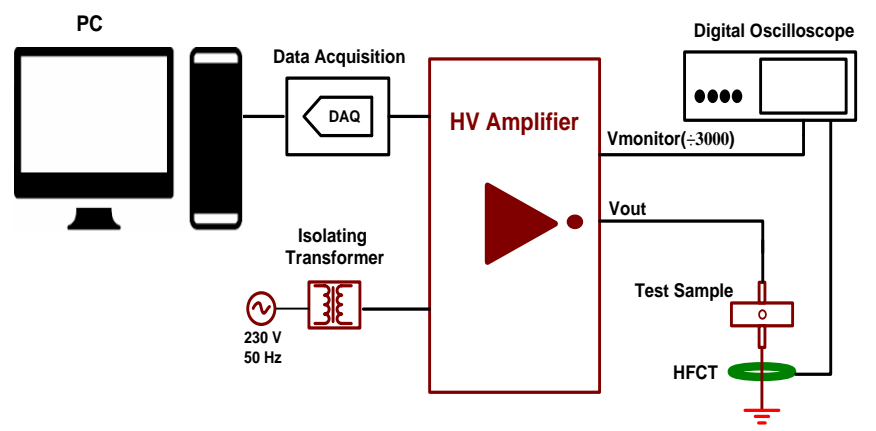

Fig. 2. Experimental setup for PD measurement under HVDC transient fields. 
According to the results presented in Figs. 3 and 4, there is no PD occurrence before polarity reversal since the applied voltages both in negative and positive polarities were lower than the PD inception voltage. However, PD pulses appear at the zero crossing point of the applied test waveform. This phenomenon might be explained thusly: Under AC voltage, the electric field distributes capacitively within a solid dielectric, which is highly dependent on the permittivity $\varepsilon$ of the insulation, but under steady state DC voltage the field distribution is governed by the conductivity of the insulation which itself depends on temperature and electric field gradients [20]. However, under transient voltages, the electric field distribution has a quasi-capacitive behaviour, i.e. the waveform variation affects the electric field distribution [3, 21]. Second, due to steadiness and unipolarity of the voltage before the polarity reversal occurs, the unipolar DC field contributes to space charge built up within the insulation due to non-homogeneity of the insulation material and unidirectional electric field. Therefore, when a polarity reversal occurs the abrupt change in the voltage and the field due to the already built-up space charge lead to an enhanced net electric field that initiates partial discharges at the defect site.

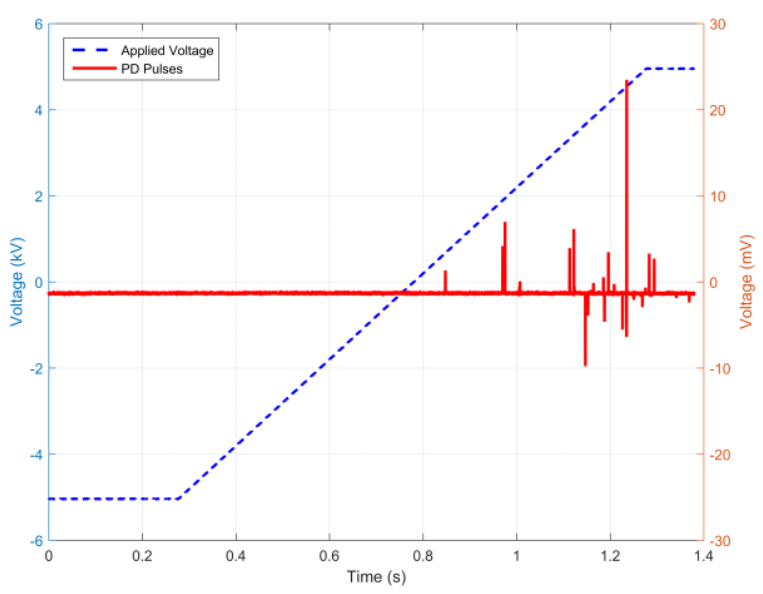

Fig. 3. PD at HVDC polarity change from negative to positive.

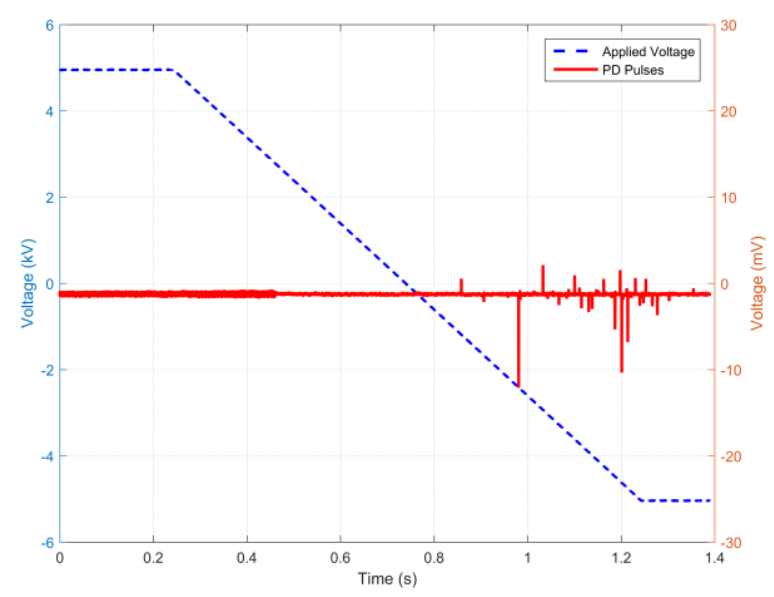

Fig. 4. PD at HVDC polarity change from positive to negative.

\section{B. PD Activity under Transient Overvoltages}

In order to study the effects of the electric fields resulting from overvoltage transients on PD behaviour, test waveforms comprised of a DC voltage superimposed with a switching impulse were generated and applied to the sample. Figs. 5 and 6 illustrate the applied test voltages in combination with the resultant PD pulses under such electric fields. In case one (Fig. 5), the steady state voltage of the applied waveform is positive DC (lower than the PD threshold of the sample), and a switching impulse of negative polarity superimposed the DC voltage that resulted in a transient polarity reversal. However, in case two (Fig. 6), the steady state voltage is a negative DC voltage and a positive switching impulse superimposing that, resulting in a transient polarity reversal with positive polarity. In both cases, as shown in the pertinent figures, the major PD pulses occur at the rising front of the transient overvoltages. This can be explained as the effect of sharp variation of the waveform that caused sudden locally enhanced electric fields, which resulted in PD incidents within the void.

Figs. 8, and 9 illustrate the test waveforms, positive and negative DC voltages superimposed with transient impulse of the same polarities, in association with the resulting PD pulses. Comparing the PD activity in these cases with that of the DC voltages superimposed with transients of opposite polarities (Figs. 6 and 7), it is apparent that the time needed for PD pulses to appear after the overvoltage incident is shorter for the latter (opposite polarities) with respect to the former (similar polarities). This may be explained by the effect of the field produced by the accumulated space charge: Under the same polarity incidents, the Poisson field from the space charges counteracts the Laplacian field from the applied external test voltages (DC in combination with transient overvoltages) and reduces the net field in the defect site, but under the case of DC superimposed with opposite polarities, the Poisson filed results in an increased net field leading to shorter statistical time lag for PD occurrence.

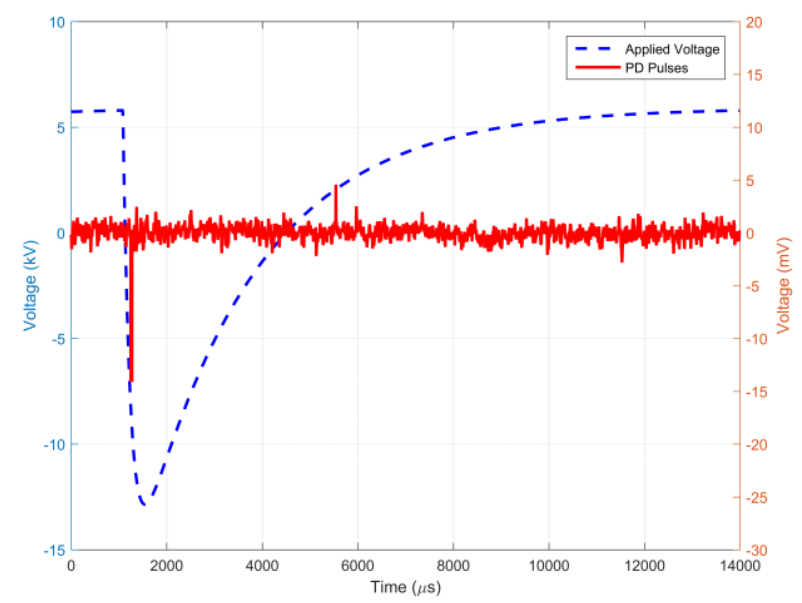

Fig. 5. PD at positive DC superimposed with negative impulse voltage. 


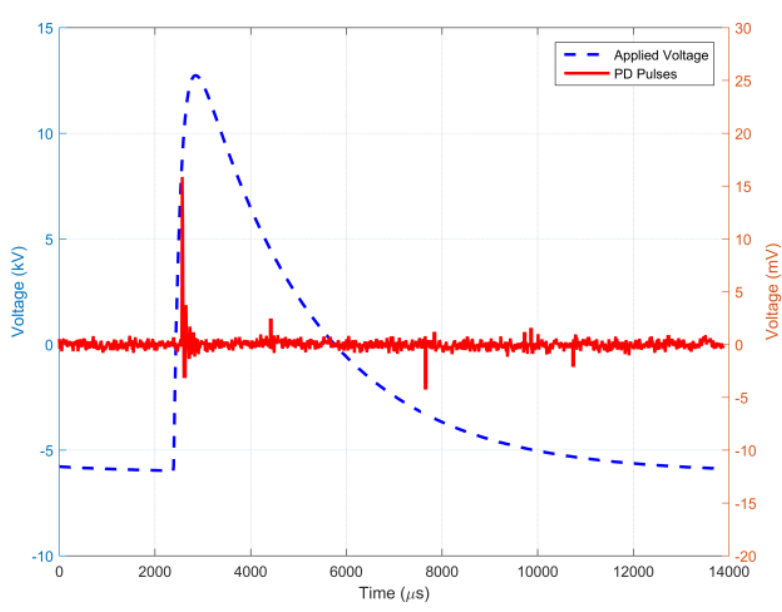

Fig. 6. PD at negative DC superimposed with positive impulse voltage.

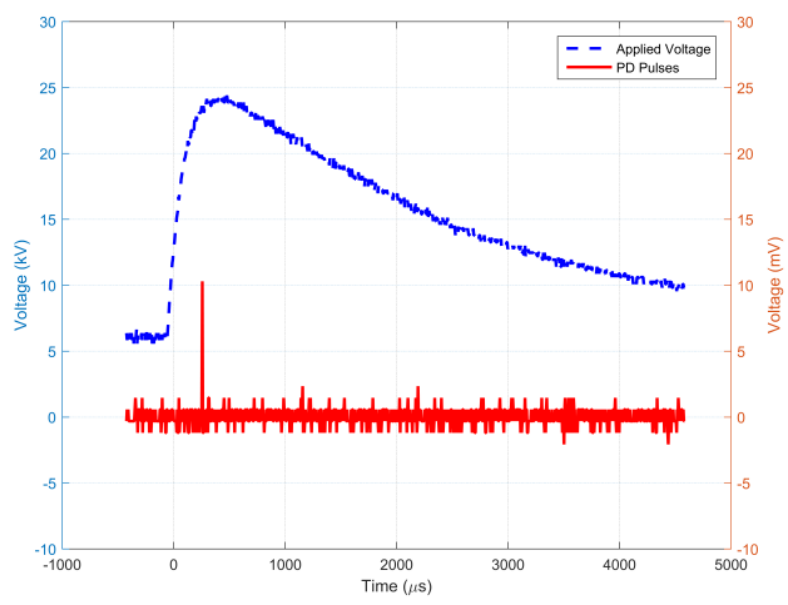

Fig. 7. PD at positive DC superimposed with positive impulse voltage.

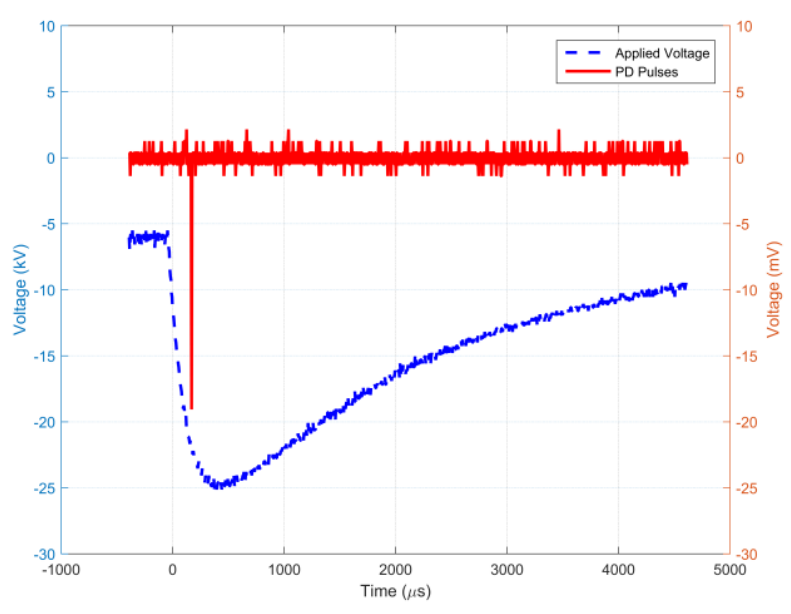

Fig. 8. PD at negative DC superimposed with negative impulse voltage.

\section{CONCLUSION}

The effect of transient conditions and polarity reversal were investigated on PD behaviour for a void defect, which was artificially embedded in slab of a polymeric insulation. The DC components of the test waveforms were kept below the PD inception voltage to investigate the effect of the superimposed transients only. Under the situation of normal polarity reversal, in both cases (positive to negative transition and vice versa) the results show that PD pulses started appearing as the zero crossing occurs. PD activity lasts until the voltage settles in its steady state. Similar results were observed under abnormal polarity reversal (i.e. the polarity reversal which occurs due to the occurrence of transient overvoltage with opposite polarity with respect to the operational DC voltage). PD pulses occurred mainly at the rising edge of the waveforms. According to the experimental results, partial discharges occur due to localized electric field enhancement caused by space charge accumulation at the site of non-homogeneity of the material, in this case mostly the embedded void. From an insulation analysis point of view, the data collected will provide insight for online PD monitoring systems and could help network operators to diagnose insulation defects through trend analysis of the PD activity, especially in cases where the steady state DC voltage is below the inception voltage of the defect.

\section{ACKNOWLEDGEMENTS}

M. Azizian Fard would like to thank Dr Norman MacLeod, technical director at the Manchester Technology Centre, for his invaluable technical information on HVDC converter station operations.

\section{REFERENCES}

[1] A. Greenwood, Electrical Transients in Power Systems, $2^{\text {nd }}$ ed., John Wiley \& Sons Inc., New York, 1991.

[2] M. Yoshinao, S. Masatoshi, A. Kazutoshi, I. Yoshiyuki, M. Shoji, K. Seiji, M. Os-amu, I. Tsuyoshi, W. Masaru, A. Shinya, and K. Shoshi, "Development of High Voltage DC-XLPE Cable System," SEI Technical Review, Apr. 2013.

[3] G. Mazzanti and M. Marzinotto, Extruded Cables for High-Voltage Direct-Current Transmission: Advances in Research and Development, 1st ed., Wiley IEEE Press: New Jersey, 2013.

[4] M. Salah Khalil, "International Research and Development Trends and Problems of HVDC Cables with Polymeric Insulation," IEEE Electr. Insul. Mag., Vol. 13, No. 6, pp. 35-47, Aug. 2002.

[5] J. C. Das, Transients in Electrical Systems Analysis, Recognition, and Mitigation, 2ndt ed., The McGraw-Hill Companies, Inc., New York, 2010 .

[6] Z. Sun, X. Zhao, J. Li and Y. Li, "Experiment Investigation of Partial Discharges under Impulse Voltage," Proceedings of the 9th International Conference on Properties and Applications of Dielectric Materials, pp. 525-529, Harbin, china, July 2009.

[7] A. Cavallini; D. Fabiani, G.C. Montanari, "Evaluation of Motor Winding Insulation Performance Under Pulse Waveforms Through Electrical Measurements," in International Wire \& Cable Conference, Guilford, pp. 293-299, 2007.

[8] J. Fothergill, "The Coming of Age of HVDC Extruded Power Cables," in Electrical Insulation Conference (EIC), pp. 124-137, Philadelphia, USA, June 2014.

[9] N. Inaba, R. Takahashi, J. Tamura, M. Kimura, A. Komura and K. Takeda, "Transient Stability Analysis of HVAC or HVDC Transmission System Based Offshore Wind Farm," In 15th International Conference on Electrical Machines and Systems (ICEMS), Sapporo, Japan, Oct. 2012

[10] S. Sasaki, T. Katayama, T. Senda and M. Sakai, "Lightning and Switching Surges in a HVDC Converter Station," Electrical Engineering in Japan, Vol 96, No. 6, 1976.

[11] IEC60071, Insulation Co-ordination - Part 1: Definitions, Principles and Rules, 2006.

[12] J. Arrillaga, High Voltage Direct Current Transmission, 1st ed., Institute of Electrical Engineering, London, 1998. 
[13] W. McDermid and T. Black, "Experience with Preventing External Flashovers in HVDC Converter Stations," IEEE International Symposium on Electrical Insulation (ISEI), pp. 81-84, Vancouver, June 2008.

[14] IEC 60060-1, High-Voltage Test Techniques - Part 1: General Definitions and Test Requirements, 2010.

[15] M. K. Bucher and C. M. Franck, "Comparison of Fault Currents in Multiterminal HVDC Grids with Different Grounding Schemes," Conference Exposition IEEE PES General Meeting, pp. 1-5, National Harbor, Jul. 2014.

[16] E. W. Kimbark. "Transient Overvoltages Caused by Monopolar Ground Fault on Bipolar DC Line: Theory and Simulation," IEEE Trans. Power App. System, pp.584-592, 1970.

[17] J. Candelaria and J.-D. Park, "VSC-HVDC System Protection: A review of Current Methods," In Proc. IEEE Power Systems Conference and Exposition (PSCE), Phoenix, Mar. 2011.

[18] P. Morshuis and J. Smit, "Partial Discharges at DC Voltage: Their Mechanism, Detection and Analysis," IEEE Trans. Dielectr. Electr. Insul., Vol. 12, pp. 328-340, April 2005.

[19] G.C. Montanari and G. Mazzanti, "Recent Developments in Insulation Life Modeling," Revue Electri. Electron, vol. 3, pp. 66-72, 1998.

[20] U. Fromm, "Interpretation of Partial Discharges at DC Voltages," IEEE Trans. Dielectr. Electr. Insul., vol. 2, pp. 761-770, Oct. 1995.

[21] B. Aladenize, R. Coelho, J.C. Assier, H. Janah, and P. Mirebeau "Field Distribution in HVDC Cables: Dependence on Insulating Materials," 5th International Conference on Insulated Power Cables, Versailles, June 1999. 